\title{
Spatial Econometric Model Analysis of Foreign Direct Investment and Haze Pollution in China
}

\author{
Dengli Tang ${ }^{1 *}, \mathrm{Li} \mathrm{Li}^{1}$, Yuanhua Yang ${ }^{2}$ \\ ${ }^{1}$ Shenzhen Graduate School, Harbin Institute of Technology, \\ Shenzhen 518055, China \\ ${ }^{2}$ Public Management School, Guangdong University of Finance and Economics, \\ Guangzhou 510000, China
}

Received: 29 September 2015

Accepted: 2 December 2015

\begin{abstract}
Increasing attention is being paid to spatial distribution characteristics of haze pollution and its relation with socioeconomic factors. This study investigates the spatial autocorrelation of haze pollution in China and the effect of foreign direct investment (FDI) on haze pollution in China using a panel data of 31 provinces over the period 2000-12. Using a widely used spatial autocorrelation index, Moran's $I$ values, the estimation results suggest that haze pollution in China has strong spatial autocorrelation and spatial clustering phenomenon. Then, our analysis using spatial econometric models further confirms the significant spatial dependence and spatial spillover effects of haze pollution in China. Meanwhile, we also find a significantly positive relationship between FDI and haze pollution in China, in which an increase of $1 \%$ in FDI, haze pollution in China will increase by $0.0235 \%$. Based on these results, we provide some important policy implications for the government to control haze pollution.
\end{abstract}

Keywords: haze pollution, foreign direct investment, spatial autocorrelation, spatial econometric models

\section{Introduction}

Haze refers to a pollution phenomenon characterized by horizontal visibility of less than $10 \mathrm{~km}$ that is caused by the light extinction of particulate matter [1]. Haze pollution not only has a negative effect on public health $[2,3]$, but also changes environmental quality and climate [4]. As the largest developing country, China is suffering severe haze pollution due to the substantial increase in anthropogenic emissions - especially in the megacity clusters such as the

*e-mail: tangdengli_2008@163.com
Yangtze River Delta, the Pearl River Delta, and the BeijingTianjin-Hebei regions [5-7]. According to the urban air quality report of 74 cities (2013) released by China's Environmental Protection Agency (EPA), only three cities' annual average concentrations of fine particulate matter $\left(\mathrm{PM}_{2.5}\right.$, particulate matter with aerodynamic diameter less than or equal to 2.5 micrometres) in 74 cities met the Chinese pollution standard.

In recent years, while many studies have investigated the sources, compositions, formation process, and influences of haze pollution in China, the systematic analysis for socioeconomic influence factors of haze pollution has not been reported. Since the reform and opening up, China 
has been the most attractive destination for foreign direct investment (FDI) in the world, along with the rapid development of economic globalization. However, China's FDI inflows during these years seemed to be accompanied by remarkable haze pollution problems, and the growing literature on the topic of FDI and environmental pollution has suggested a potential interaction between FDI and environmental pollution. Thus, what is the possible relationship between continuous increases of FDI inflows and haze pollution in China? Should the inflows of FDI be responsible for haze pollution in China? It is imperative to answer these questions.

Therefore, the aims of this paper were to:

1. Estimate the spatial autocorrelation of haze pollution in China using exploratory spatial data analysis (ESDA).

2. Investigate the effects of FDI on haze pollution in China using spatial econometric models, including spatial lag model (SLM) and spatial error model (SEM).

\section{Literature Review}

In an increasingly integrated world, one of the most controversial debates today is whether FDI inflows are changing developing countries into pollution havens. This is what is termed the pollution haven hypothesis ( $\mathrm{PHH})$, and it implies that developed countries tend to transfer pollution-intensive industries to developing countries with laxer environmental regulations through FDI inflows in order to gain lower labor costs and competitiveness in the international market. Early studies failed to establish empirical support for PHH. Research by Jaffe et al. (1995) and Wheeler (2001) suggest that there is hardly any systematic evidence for environmental pollution effect of FDI by a review of literature $[8,9]$. Based on a sample of 24 transition countries, Smarzynska and Wei (2004) also conclude no evidence for pollution haven theory [10]. However, recent studies have examined the effects of FDI inflows on environmental pollution from different perspectives, with mixed findings.

As for evidence supporting $\mathrm{PHH}$, List and Co (2000) use a conditional logit model and state-level data from 1986-93 to evaluate the impact of environmental regulations on foreign multinational corporations' new plant location decisions. Their empirical results suggest that foreign investment is sensitive to pollution regulations [11]. Based on panel data of China's 29 provinces' industrial $\mathrm{SO}_{2}$ emissions, He (2006) constructs a fiveequation simultaneous model to study the FDI-pollution relationship during 1999-2001. The estimation results find that the total influence of FDI on industrial $\mathrm{SO}_{2}$ emissions is very small. With an increase of $1 \%$ in FDI capital stock, industrial $\mathrm{SO}_{2}$ emissions will rise by $0.098 \%$ [12]. Wagner and Timmins (2009) also test PHH using panel data on outward FDI flows of various industries in the German manufacturing sector. They find robust evidence of a pollution haven effect for the chemical industry [13].

Similarly, Cole et al. (2011) investigate incomepollution relationship using data for 112 Chinese cities over the period 2001 to 2004 . Their results provide some evidence for the existence of a pollution haven effect in China [14]. Additionally, Chung (2014) studies how environmental regulation shapes the pattern of FDI. They find strong evidence that polluting industries tend to invest more in countries with laxer environmental regulations, which supports $\mathrm{PHH}$ [15]. Using the bounds testing approach and Granger causality methodology, Lau et al. (2014) find that both FDI and trade lead to degradation in environmental quality in Malaysia [16].

Other studies, however, do not support the PHH, but support the idea that FDI helps decrease environmental pollution $[17,18]$ - the so-called pollution halo hypothesis proposed by Walter and Ugelow (1979) [19]. Researchers such as Birdsall and Wheeler (1993) argue that the more open a country is, the more likely it is to attract cleaner industries. They conclude that FDI can impact environmental quality in a positive way for some developing countries [17]. Then Eskeland and Harrison (2003) challenge the $\mathrm{PHH}$, suggesting that multinational firms in developing countries are less polluting than their peers, and show that there is not robust evidence on PHH [20]. Using a north-south market share game model in a two-country setting, Dong et al. (2012) studied the relationship between FDI and environmental regulation. Results show that if both market sizes are small, FDI will increase host countries' emission standard, resulting in a "race-to-the-top" effect, but if both market sizes are large enough, FDI will not change emission standards [21]. Tang and Tan (2015) also investigate the dynamic relationship between carbon dioxide $\left(\mathrm{CO}_{2}\right)$ emissions and FDI in Vietnam. The results reveal that FDI is found to be negatively affecting $\mathrm{CO}_{2}$ emissions [22].

Moreover, some scholars advocate that the influence of FDI on environmental pollution is the comprehensive result of multiple channels, including scale, composition, and technique effects [23]. Based on panel data of China's 29 provinces from 1992 to 2004, Bao et al. (2011) investigate the environmental effects of FDI by applying simultaneous equations. The results show that while the technique effect of FDI has a negative effect relevant to environmental pollution, the composition effect and scale effect of FDI are both positive. That is to say, the effect of FDI on environmental pollution mainly contributes to the three effects [24]. Then, Lan et al. (2012) also examine the relationship between FDI and pollution in China by using provincial socioeconomic and environmental data. They find that the effect of FDI on environmental pollution depends on the level of human capital. FDI is negatively related to pollution with the higher levels of human capital, and vice versa [25].

In summary, previous studies examined the relationship between FDI and environmental pollution and obtained a rich understanding about the environmental effects of FDI. However, it is undeniable that there are still some limitations. One is that scholars do not consider spatial autocorrelation or spatial spillover effects of FDI and environmental pollution. The new economic geography pointed out that economic activity clustering often occurs 
at all geographical levels [26]. Another limitation is that most studies in the current literature mainly select $\mathrm{SO}_{2}$ and $\mathrm{CO}_{2}$ as indicators of environmental pollution, and other pollution indicators, such as $\mathrm{PM}_{25}$ or $\mathrm{PM}_{10}$, are ignored. Furthermore, when investigating the relationship between FDI and haze pollution, it seems that it is necessary to take spatial factors and other control variables into account. Therefore, compared with previous research, the contributions of this study are mainly embodied in three aspects. First, this paper is the first study that uses panel data of 31 provinces' annual averaged $\mathrm{PM}_{2.5}$ concentrations to investigate the relationship of FDI and haze pollution in China. Second, we apply spatial econometric models to estimate the effect of FDI on haze pollution in China and to ensure that the spatial autocorrelation of haze pollution be taken into consideration. Third, to minimize deviations of estimation results caused by the other omitted variables, a set of control variables are added into spatial econometric models.

\section{Empirical Methods}

\section{Exploratory Spatial Data Analysis (ESDA)}

ESDA is a method of describing spatial autocorrelation, which is employed to detect spatial properties of a phenomenon [27]. It can be divided into global spatial autocorrelation analysis and local spatial autocorrelation analysis. Global spatial autocorrelation analysis is used to describe spatial distribution characteristics in the entire study area, and often assessed by global Moran's I index and Geary's C statistics. In this study, we apply global Moran's $I$ as the measure index to understand spatial autocorrelation of haze pollution in China. Global Moran's $I$ index is defined as:

$$
\begin{aligned}
I & =\frac{n \sum_{i=1}^{n} \sum_{k=1}^{n} w_{i k}\left(x_{i}-\bar{x}\right)\left(x_{k}-\bar{x}\right)}{\sum_{i=1}^{n} \sum_{k=1}^{n} w_{i k} \sum_{i=1}^{n}\left(x_{i}-\bar{x}\right)^{2}}= \\
& =\frac{\sum_{i=1}^{n} \sum_{k=1}^{n} w_{i k}\left(x_{i}-\bar{x}\right)\left(x_{k}-\bar{x}\right)}{S^{2} \sum_{i=1}^{n} \sum_{k=1}^{n} w_{i k}}
\end{aligned}
$$

$\ldots$ where $x_{i}$ and $x_{k}$ are annual averaged $\mathrm{PM}_{2.5}$ concentrations from regions $i$ and $k$, respectively; $n$ is the total number of regions; $S^{2}$ is variance of observation variable; and $w_{i k}$ is a spatial weight matrix, which refers to spatial layout of observation variables between different regions. In this paper, we build up the spatial weight matrix in China based on a spatial adjacency relationship, namely that $w_{i k}$ is equal to 1 if region $i$ and region $k$ are adjacent to each other; otherwise, $w_{i k}$ is equal to 0 .

Local spatial autocorrelation analysis is used to evaluate spatial agglomeration, spatial heterogeneity or spatial regimes among regions. It can be measured by G statistics, Moran scatter plot, and local indicators of spatial association (LISA). Local Moran's I, which is often called LISA, is applied to measure local clustering phenomenon between regions $i$ and $k$. Local Moran's $I$ index is expressed as:

$$
I_{i}=\frac{\left(x_{i}-\bar{x}\right)}{S^{2}} \sum_{k=1}^{n} w_{i k}\left(x_{k}-\bar{x}\right)
$$

...where $x_{i}, x_{k}, n, w_{i k}$, and $S^{2}$ are the same as calculating global Moran's index. Similar to global Moran's $I$, a low (negative) local Moran's I value indicates negative spatial autocorrelation, while a high (positive) local Moran's I value indicates positive spatial autocorrelation.

\section{Model Specification}

Early researchers such as Grossman and Krueger (1995) found an inverted U-shaped relationship between economic development and pollution emissions, the socalled environmental Kuznets curve (EKC) [28]. FDI has direct and indirect effects on environmental quality through its effect on GDP [24]. In this study, econometric model analysis will bring invalid results if we ignore economic growth and just use FDI as an independent variable. Therefore, according to the general equilibrium model of Antweiler et al. (2001) [29] and EKC, the basic econometric model is shown below:

$$
\begin{gathered}
\ln H_{i t}=\beta_{0}+\beta_{1} \ln G D P_{i t}+\beta_{2} \ln ^{2} G D P_{i t}+ \\
+\beta_{3} \ln ^{3} G D P_{i t}+\beta_{4} \ln F D I_{i t}+\beta_{5} X_{i t}+\varepsilon_{i t}
\end{gathered}
$$

...where subscripts $i$ and $t$ represent region and year, respectively; $\beta_{0}$ is the region-specific fixed effect; $\varepsilon_{i t}$ is the error term; $H_{i t}$ is haze pollution indicator, and this study will use $\mathrm{PM}_{2.5}$ statistics to measure haze pollution; $G D P_{i t}$ is gross domestic product; $F D I_{i t}$ denotes foreign direct investment, and $X_{i t}$ represents a set of control variables that affect pollution, including industrial structure (IS), technical progress (TP), and environmental regulation (ER).

Equation (3) not only neglects spatial autocorrelation of haze pollution among regions, but also does not consider spatial spillover effects of haze pollution. When spatial autocorrelation exists, the ordinary least squares (OLS) estimation would lead to invalid results. Following Anselin (1995), we use spatial econometric models, including spatial lag model (SLM) and spatial error model (SEM) to estimate the effect of FDI on haze pollution [27]. In this study, the SLM assumes that spatial autocorrelation stems from dependent variables, investigating the spatial spillover effects of adjacent regions' haze pollution on local regions' haze pollution. A SLM is given by:

$$
\begin{gathered}
\ln H_{i t}=\rho w \ln H_{i t}+\beta_{0}+\beta_{1} \ln G D P_{i t}+\beta_{2} \ln ^{2} G D P_{i t}+ \\
+\beta_{3} \ln ^{3} G D P_{i t}+\beta_{4} \ln F D I_{i t}+\beta_{5} X_{i t}+\varepsilon_{i t} \\
\varepsilon_{i t} \sim N\left(0, \sigma_{i t}^{2}\right)
\end{gathered}
$$

...where $w \ln H_{i \mathrm{t}}$ denotes spatial lag variable, $\rho$ is the spatial autoregressive coefficient, and $\mathrm{w}$ is the spatial weight matrix of size $n \times n$. 
The SEM assumes that spatial autocorrelation stems from the error shock of adjacent regions on dependent variables, evaluating the effects of adjacent regions on local observation values. The expression for SEM is:

$$
\begin{gathered}
\ln H_{i t}=\beta_{0}+\beta_{1} \ln G D P_{i t}+\beta_{2} \ln ^{2} G D P_{i t}+\beta_{3} \ln ^{3} G D P_{i t}+ \\
+\beta_{4} \ln F D I_{i t}+\beta_{5} X_{i t}+\varepsilon_{i t} \\
\varepsilon_{i t}=\lambda w_{\varepsilon}+\mu_{i t}, \quad \mu_{i t} \sim N\left(0, \sigma_{i t}^{2}\right)
\end{gathered}
$$

...where $\lambda$ is spatial error autoregressive coefficient and $\mu_{\mathrm{it}}$ is the vector of random errors meeting normal distribution.

\section{Data Sources}

Our paper uses panel data of 31 provinces in China during 2000-12. All the original economic data are taken from the National Statistical Yearbook (2001-13) and China Statistical Yearbook for Regional Economy (200113). The data of annual averaged $\mathrm{PM}_{2.5}$ concentrations are collected from Battelle Memorial Institute, CIESIE [30], and these data basically agree with the judgment of China's haze pollution situation reported by China's EPA in February 2012. Table 1 presents descriptive statistics for variables and data.

\section{Results and Discussion}

\section{Global Spatial Autocorrelation Analysis}

Table 2 shows the global Moran's $I$ values for 31 provinces in China and the test results. During 200012, global Moran's $I$ values of haze pollution vary from 0.5433 to 0.6524 , and the exact values are $0.5433,0.5855$, $0.6154,0.6414,0.6507,0.6524,0.6354,0.6476$, $0.6505,0.6483,0.6381,0.6321$, and 0.6325 . Meanwhile, global Moran's I values between 2000 and 2012 are highly significant at the 0.01 significance level, which indicates that haze pollution in China exists in a remarkably spatial autocorrelation. In other words, haze pollution in China is not distributed randomly, but shows spatial clustering phenomenon between some regions - namely that heavily haze-polluted regions tend to be adjacent to heavily hazepolluted regions, with the same noted for lightly hazepolluted regions.

\section{Local Spatial Autocorrelation Analysis}

Although global Moran's I values provide strong evidence of spatial autocorrelation of haze pollution over the entire study area, local spatial autocorrelation tests are also run in order to visually explore spatial autocorrelation of haze pollution using Moran scatter plots and LISA. Fig. 1 presents the Moran scatter plots of haze pollution in 2000, 2006, and 2012, indicating that most regions are located in the first and third quadrants, but there are still two to five regions in the second and forth quadrants. Specifically speaking, the first quadrant contains 14,15 , and 14 regions for the years of 2000, 2006, and 2012, respectively; the third quadrant contains 12,13 , and 15 regions for the years 2000, 2006, and 2012, respectively. So the number of regions located in the first quadrant and the third quadrant account for $84 \%, 90 \%$, and $94 \%$ of the total number of regions, respectively. The results further confirm that spatial distribution of haze pollution in China shows significant positive autocorrelation. In other words, most regions and adjacent regions show similar clustering characteristics, which means heavily haze-polluted regions tend to be adjacent to heavily haze-polluted regions and vice versa.

The global Moran's I values and Moran scatter plots show that haze pollution in China exists with significant spatial autocorrelation. In order to further detect the local spatial autocorrelation patterns, we conduct LISA analysis. As indicated in Fig. 2, local spatial clustering phenomenon of haze pollution in China is obvious. The high-high type is mainly located in regions with low altitude, a developed economy, and a large population, especially the eastern part of China. Over 13 years, the high-high type is almost unchanged, which takes Hebei and Henan provinces as the core and is composed of Beijing, Tianjin, Shandong, Hubei, Jiangsu, and Anhui provinces.

The low-low type can be classified into two categories. The first category is found in the western part of China,

Table 1. Descriptive statistics for variables.

\begin{tabular}{|c|c|c|c|c|c|c|}
\hline Variables & Unit & Mean & Median & SD & Max & Min \\
\hline $\ln H$ & ug/m & 3.4637 & 3.5807 & 0.6423 & 4.4336 & 0.8286 \\
\hline $\ln G D P$ & hundred million yuan & 8.3601 & 8.5217 & 1.113 & 10.6657 & 4.769 \\
\hline $\ln ^{2} G D P$ & hundred million yuan & 71.1275 & 72.6194 & 17.781 & 113.7573 & 22.7432 \\
\hline $\ln ^{3} G D P$ & hundred million yuan & 614.2811 & 618.8411 & 219.2323 & 1213.3017 & 108.4623 \\
\hline $\ln F D I$ & hundred million yuan & 4.2433 & 4.4819 & 1.9206 & 7.3205 & -6.3771 \\
\hline$I S$ & $\%$ & 46.6047 & 48.4 & 8.2255 & 61.5 & 19.8 \\
\hline $\ln T P$ & ten thousand yuan/person & 1.3677 & 1.3712 & 0.6346 & 3.2145 & -1.204 \\
\hline$E R$ & $\%$ & 1.2128 & 1.13 & 0.6534 & 4.66 & 0.01 \\
\hline
\end{tabular}


Table 2. Global Moran's $I$ of haze pollution in China's 31 provinces, 2000-12.

\begin{tabular}{|c|c|c|c|c|c|}
\hline Years & Moran's $I$ & $\mathrm{E}(\mathrm{I})$ & Mean & $\mathrm{SD}(\mathrm{I})$ & P value \\
\hline 2000 & 0.5433 & -0.0333 & -0.0322 & 0.1142 & 0.0010 \\
\hline 2001 & 0.5855 & -0.0333 & -0.0293 & 0.1147 & 0.0010 \\
\hline 2002 & 0.6154 & -0.0333 & -0.0271 & 0.1124 & 0.0010 \\
\hline 2003 & 0.6414 & -0.0333 & -0.0306 & 0.1136 & 0.0010 \\
\hline 2004 & 0.6507 & -0.0333 & -0.0237 & 0.1159 & 0.0010 \\
\hline 2005 & 0.6524 & -0.0333 & -0.0294 & 0.1091 & 0.0010 \\
\hline 2006 & 0.6354 & -0.0333 & -0.0331 & 0.1166 & 0.0010 \\
\hline 2007 & 0.6476 & -0.0333 & -0.0349 & 0.1154 & 0.0010 \\
\hline 2008 & 0.6505 & -0.0333 & -0.0338 & 0.1154 & 0.0010 \\
\hline 2009 & 0.6483 & -0.0333 & -0.0290 & 0.1147 & 0.0010 \\
\hline 2010 & 0.6381 & -0.0333 & -0.0332 & 0.1170 & 0.0010 \\
\hline 2011 & 0.6321 & -0.0333 & -0.0322 & 0.1150 & 0.0010 \\
\hline 2012 & 0.6325 & -0.0333 & -0.0332 & 0.1127 & 0.0010 \\
\hline
\end{tabular}

covering Tibet, Gansu, Xinjiang, Qinghai, and Sichuan regions. The second category of high-low type is located in Jilin and Heilongjiang provinces. Besides, the low-high type also has existed for 13 years, which takes Hainan province as the core. Therefore, we hold that spatial cluster effects of haze pollution in China are obvious and stable, and high-high clustering regions are mainly distributed in central China, the Beijing-Tianjin-Hebei region, and the Yangtze River Delta region.

\section{Spatial Autocorrelation Test and Model Selection}

As discussed above, SLM and SEM can be conducted to spatial regression analysis. Here, we make a comparison between SLM and SEM, and choose a better model to test the relationship of FDI and haze pollution. Anselin (1996) put forward a spatial regression model decision rule: first, Moran's $I$ values decide whether or not to introduce a spatial variable; second, if the Lagrange multiplier (lag) value is more significant than Lagrange multiplier (error) value, the appropriate model is SLM. Conversely, if Lagrange multiplier (error) value is more significant than Lagrange multiplier (lag) value, the appropriate model is SEM; third, if Lagrange multiplier (lag) and Lagrange multiplier (error) values are similar and significant, robust Lagrange multiplier (lag) and robust Lagrange multiplier (error) tests are necessary [31]. The results of the spatial autocorrelation test of haze pollution are listed in Table 3.

As shown in Table 3, Moran's $I$ value is 0.4713 at the 0.01 significance level, indicating that haze pollution in China has positive spatial autocorrelation. Meanwhile, Lagrange multiplier (lag) value and Lagrange multiplier (error) value are high, and are significant at the 0.01 significance level. We further compare robust LM values to judge which model is more appropriate. The robust Lagrange multiplier (lag) value is significant at the 0.01 significance level, and the robust Lagrange multiplier (error) value is not significant at the 0.1 significance level. Thus, we choose SLM over SEM to investigate the effect of FDI on haze pollution in China.

\section{Spatial Econometric Test of FDI and Haze Pollution}

Lagrange multiplier values from OLS can decide which model is better between SLM and SEM. Nevertheless, previous studies have shown that OLS estimation may yield biased estimates if spatial autocorrelation variables exist [32]. In this paper, global Moran's I values confirmed spatial autocorrelation of haze pollution in China, so spatial model estimation should apply maximum likelihood estimation (ML) rather than OLS estimation. Besides, when sample regression analysis is limited to some certain individuals, the fixed effects model is a better selection [33]. Thus, spatial fixed effects models are used to test the relationship between FDI and haze pollution, which can be divided into no spatial and time-specific fixed effects (nonFE), spatial fixed effects (SFE), time-period fixed effects (TPFE), and spatial and time-period fixed effects (STPFE). The estimation results of SLM and SEM are listed in Table 4.

By comparing the spatial regression analysis results of SLM and SEM in Table 4, the log likelihood (Log-L) and
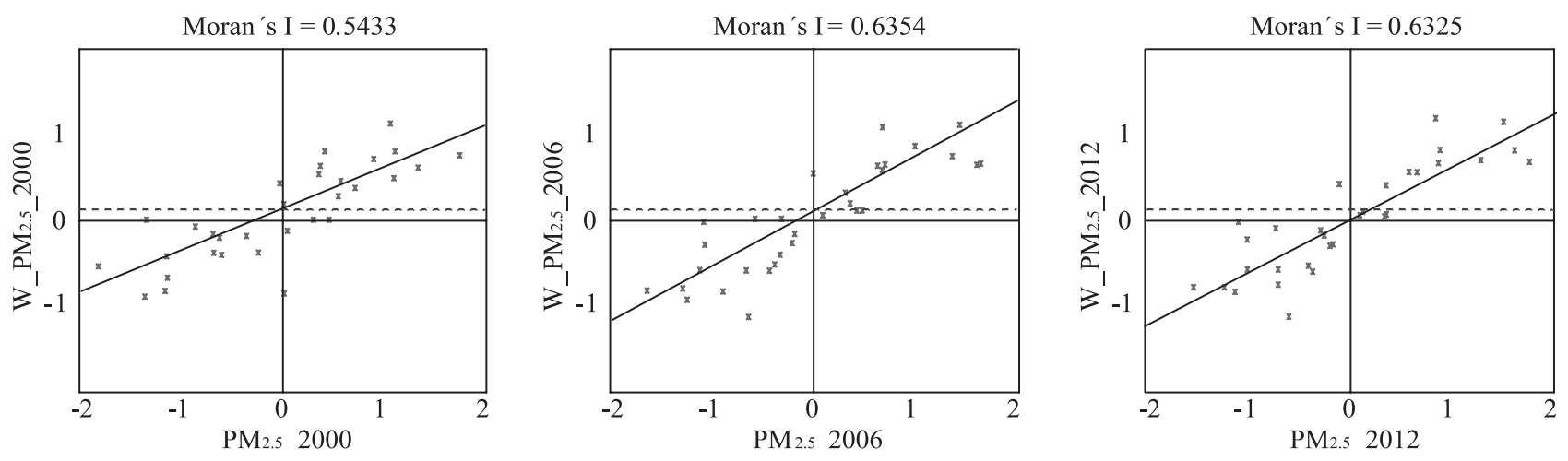

Fig. 1. The Moran scatter plot for haze pollution in China. 

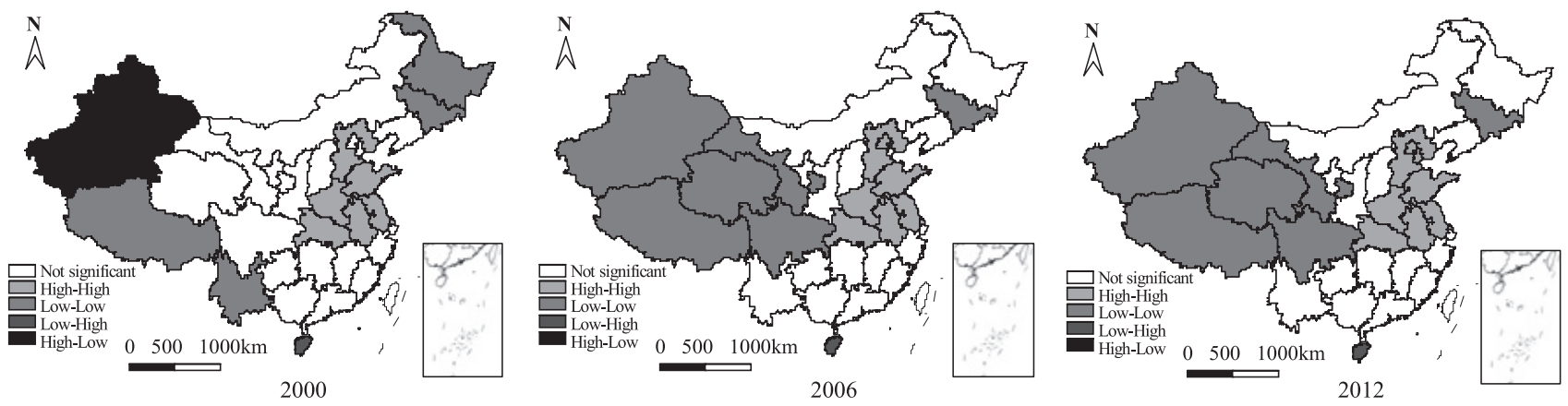

Fig. 2. LISA cluster maps of haze pollution in China.

$\mathrm{R}^{2}$ values are more significant in SLM, and the STPFE of SLM is an optimal choice, indicating that haze pollution in China has obvious spatial characteristics - namely that the changes of haze pollution in a region will affect its adjacent regions. Therefore, as explained earlier, SLM is applied to explain the effect of FDI on haze pollution in China, and some useful conclusions are obtained.

First, geographical proximity has a positive effect on haze pollution in China. Table 4 shows that the spatial lag coefficient is positive and statistically significant (at the

Table 3. Spatial autocorrelation test of haze pollution.

\begin{tabular}{|c|c|c|c|c|}
\hline $\begin{array}{c}\text { Moran's } I \\
(Z \text { value }\end{array}$ & $\begin{array}{c}\text { Lagrange Multiplier } \\
\text { (lag) }\end{array}$ & $\begin{array}{c}\text { Robust Lagrange Multiplier } \\
\text { (P value) }\end{array}$ & $\begin{array}{c}\text { Lagrange Multiplier } \\
\text { (error) } \\
\text { (P value) }\end{array}$ & $\begin{array}{c}\text { Robust Lagrange Multiplier } \\
\text { (error) } \\
\text { (P value) }\end{array}$ \\
\hline $0.4713 * * *$ & 216.1552 & 22.5855 & 194.2436 & 0.6739 \\
$(13.5348)$ & $(0.0000)$ & $(0.0000)$ & $(0.0000)$ & $(0.412)$ \\
\hline
\end{tabular}

Table 4. Estimation results of SLM and SEM.

\begin{tabular}{|c|c|c|c|c|c|c|c|c|}
\hline \multirow{2}{*}{ Variables } & \multicolumn{4}{|c|}{ SLM } & \multicolumn{4}{|c|}{ SEM } \\
\hline & nonFE & SFE & TPFE & STPFE & nonFE & SFE & TPFE & STPFE \\
\hline Constant & $\begin{array}{c}-16.7820 * * * \\
(-6.0751)\end{array}$ & & & & $\begin{array}{c}-14.0797 * * * \\
(-5.7619)\end{array}$ & & & \\
\hline $\ln \mathrm{GDP}$ & $\begin{array}{c}5.6756^{* * *} \\
(5.2275)\end{array}$ & $\begin{array}{l}0.7380^{* *} \\
(2.3134)\end{array}$ & $\begin{array}{c}5.8518^{* * *} \\
(5.5169)\end{array}$ & $\begin{array}{l}0.6539^{*} \\
(1.9592)\end{array}$ & $\begin{array}{c}5.6761 * * * \\
(5.8750)\end{array}$ & $\begin{array}{c}1.3220^{* * *} \\
(4.3728)\end{array}$ & $\begin{array}{c}5.6807^{* * * *} \\
(5.7898)\end{array}$ & $\begin{array}{c}1.1352 * * * \\
(3.7882)\end{array}$ \\
\hline $\ln ^{2} \mathrm{GDP}$ & $\begin{array}{c}-0.6239 * * * \\
(-4.4717)\end{array}$ & $\begin{array}{c}-0.0950^{* *} \\
(-2.3376)\end{array}$ & $\begin{array}{c}-0.6509 * * * \\
(-4.7723)\end{array}$ & $\begin{array}{l}-0.0918^{* *} \\
(-2.2392)\end{array}$ & $\begin{array}{c}-0.6322 * * * \\
(-5.0917)\end{array}$ & $\begin{array}{c}-0.1403 * * * \\
(-3.6566)\end{array}$ & $\begin{array}{c}-0.6328 * * * \\
(-5.0187)\end{array}$ & $\begin{array}{c}-0.1550^{* * * *} \\
(-4.0322)\end{array}$ \\
\hline $1 n^{3} \mathrm{GDP}$ & $\begin{array}{c}0.0232 * * * \\
(3.9481)\end{array}$ & $\begin{array}{l}0.0043 * * \\
(2.4809)\end{array}$ & $\begin{array}{c}0.0249 * * * \\
(4.3167)\end{array}$ & $\begin{array}{l}0.0043 * * \\
(2.4777)\end{array}$ & $\begin{array}{c}0.0238^{* * *} \\
(4.5533)\end{array}$ & $\begin{array}{c}0.0056^{* * *} \\
(3.4781)\end{array}$ & $\begin{array}{c}0.0238^{* * *} \\
(4.4885)\end{array}$ & $\begin{array}{c}0.0065^{* * * *} \\
(4.016)\end{array}$ \\
\hline $\ln \mathrm{FDI}$ & $\begin{array}{c}-0.0507 * * * \\
(-3.0455)\end{array}$ & $\begin{array}{c}0.0301 * * * \\
(4.2186)\end{array}$ & $\begin{array}{c}-0.0764 * * * \\
(-4.4593)\end{array}$ & $\begin{array}{c}0.0235 * * * \\
(3.2355)\end{array}$ & $\begin{array}{c}-0.0362 * * \\
(-2.0997)\end{array}$ & $\begin{array}{c}0.0226^{* * * *} \\
(3.2502)\end{array}$ & $\begin{array}{c}-0.0362 * * \\
(-2.0671)\end{array}$ & $\begin{array}{c}0.0190 * * * \\
(2.7633)\end{array}$ \\
\hline IS & $\begin{array}{c}0.0089^{* * * *} \\
(3.8708)\end{array}$ & $\begin{array}{c}0.0009 \\
(0.7557)\end{array}$ & $\begin{array}{c}0.0082 * * * \\
(3.6230)\end{array}$ & $\begin{array}{c}0.0008 \\
(0.5925)\end{array}$ & $\begin{array}{c}0.0082 * * * \\
(4.0679)\end{array}$ & $\begin{array}{c}0.0001 \\
(0.1091)\end{array}$ & $\begin{array}{c}0.0082 * * * \\
(4.0057)\end{array}$ & $\begin{array}{l}0.0028 * * \\
(2.2496)\end{array}$ \\
\hline $\ln \mathrm{TP}$ & $\begin{array}{c}0.0271 \\
(0.9049)\end{array}$ & $\begin{array}{c}-0.0728 * * * \\
(-2.9525)\end{array}$ & $\begin{array}{c}0.0636^{* *} \\
(2.1177)\end{array}$ & $\begin{array}{c}-0.1213 * * * \\
(-4.5367)\end{array}$ & $\begin{array}{c}0.0445 \\
(1.3289)\end{array}$ & $\begin{array}{c}-0.0545^{* *} \\
(-2.1022)\end{array}$ & $\begin{array}{c}0.0436 \\
(1.2861)\end{array}$ & $\begin{array}{c}-0.1026^{* * *} \\
(-3.9118)\end{array}$ \\
\hline ER & $\begin{array}{c}0.1029 * * * \\
(3.8283)\end{array}$ & $\begin{array}{c}0.0049 \\
(0.5788)\end{array}$ & $\begin{array}{c}0.1320^{* * * *} \\
(4.9412)\end{array}$ & $\begin{array}{c}0.0110 \\
(1.2649)\end{array}$ & $\begin{array}{c}0.1089 * * * \\
(4.6170)\end{array}$ & $\begin{array}{c}0.0055 \\
(0.7101)\end{array}$ & $\begin{array}{c}0.1089 * * * \\
(4.5510)\end{array}$ & $\begin{array}{c}0.0069 \\
(0.8931)\end{array}$ \\
\hline$\rho / \lambda$ & $\begin{array}{c}0.7270 * * * \\
(27.1436)\end{array}$ & $\begin{array}{c}0.7940 * * * \\
(28.5249)\end{array}$ & $\begin{array}{c}0.7470 * * * \\
(27.7699)\end{array}$ & $\begin{array}{c}0.7262 * * * \\
(21.3018)\end{array}$ & $\begin{array}{c}0.8450 * * * \\
(36.4978)\end{array}$ & $\begin{array}{c}0.8250 * * * \\
(32.5869)\end{array}$ & $\begin{array}{c}0.8460 * * * \\
(36.7123)\end{array}$ & $\begin{array}{c}0.7894 * * * \\
(27.3093)\end{array}$ \\
\hline $\mathrm{R}^{2}$ & 0.7703 & 0.9899 & 0.7891 & 0.9902 & 0.4106 & 0.9724 & 0.4160 & 0.9817 \\
\hline Log-L & -129.9090 & 489.2163 & -116.1419 & 504.8928 & -124.0508 & 479.4184 & -123.99 & 502.9664 \\
\hline
\end{tabular}

Note: Figures in parentheses are t-statistics, $* * *, * *$ and $*$ indicate the significance at $1 \%, 5 \%$, and $10 \%$ level, respectively. 
$1 \%$ level), which means that haze pollution in China has significant spatial dependence and strong spillover effect, namely that an increase of $1 \%$ in a region's haze pollution will lead to an increase of $0.7262 \%$ in haze pollution of its adjacent regions. Some scholars have pointed out that the spatial factor actually can influence haze pollution $[6,34]$. On one hand, natural geographic factors such as wind direction and wind velocity lead to transboundary transportation of haze pollution; on the other hand, industrial transfer can also deepen the correlation of regional haze pollution. In this circumstance, local government must consider how to make the global planning of industrial structure adjustment to realize green industry strategy.

Second, the regression coefficient of FDI is 0.0235 , which is significant at the 0.01 significance level. This means that FDI has a positive effect on haze pollution in China, and thus does not help decrease haze pollution. This result provides support for PHH. In the early stages of economic development, developed countries tend to move pollution-intensive industries to developing countries with laxer environmental regulations in order to reduce their production costs and gain competitiveness in the international market, so developing countries are engaged in the production of dirty industry, and then become the pollution haven of developed countries. In China, the competition is very intense between local governments under the incentive mechanism with GDP as an important achievement appraisal standard. In order to promote the increase of GDP, underdeveloped areas without competitive advantage attracted more foreign investments with high-polluting industries.

Third, all the regression coefficients of GDP are significant at the 0.1 significance level, with the estimated values of being positive, negative, and positive, respectively. Therefore, the relationship of GDP and haze pollution in China presents the $\mathrm{N}$-shaped curve. That is to say, as GDP increases, the degree of haze pollution first increased, then decreased, and then further increased. This result confirms that the EKC relationship between GDP and haze pollution in China does not exist, and with the elapse of time, the increase of GDP will finally aggravate haze pollution in China. So it is of strategic significance for the sustainable development of a national economy to practice the scientific view of development and transform the path of economic development.

Moreover, Table 4 further analyzes the effects of other control variables on haze pollution in China. The regression coefficient of TP is -0.1213 at the 0.01 significance level, meaning that $\mathrm{TP}$ helps reduce haze pollution in China and thus has a positive effect on haze pollution control. Meanwhile, the estimation results show that IS and ER are not significant at the 0.1 significance level. IS has a positive relationship with haze pollution in China, implying that the degree of haze pollution will increase by $0.0008 \%$ with a $1 \%$ increase of the proportion of secondary industry to total GDP. At present, our country is still in the early stage of industrialization and industrial energy consumption level has been high, which impose heavy pressure on environmental quality. The regression coefficient of ER is also positive, namely in that environmental pollution investment does not help decrease haze pollution, but aggravates haze pollution. This indicates that, compared with the continued growth of GDP, haze pollution control investment is far from enough.

\section{Conclusions}

This study first analyzes spatial autocorrelation of haze pollution in China over the 2000-12 period using the ESDA method, and then uses spatial econometric models, including SLM and SEM, to evaluate the environmental effects of FDI. The main conclusions of the study are as follows.

First, global spatial autocorrelation analysis results show that haze pollution in China has strong spatial autocorrelation, which illustrates that heavily hazepolluted regions tend to be adjacent to heavily hazepolluted regions and vice versa. Moreover, the spatial clustering phenomenon is obvious and stable, where highhigh clustering regions are mainly distributed in central China, the Beijing-Tianjin-Hebei region and the Yangtze River Delta region. Second, our analysis using spatial econometric models further confirms significant spatial dependence of haze pollution in China. Moreover, the estimation results reveal that an increase of $1 \%$ in FDI will lead to an increase of $0.0235 \%$ in haze pollution, and thus FDI aggravates haze pollution in China. Third, we also investigate the effects of other control variables on haze pollution in China, and our estimation results show that GDP does play an important role in haze pollution, and that TP has significant and positive effects on haze pollution. Meanwhile, we find that IS and ER cannot help decrease haze pollution in China.

Our research conclusions have important policy implications that are beneficial to understanding spatial autocorrelation of haze pollution in China and its relationship with FDI. First, the establishment of joint prevention and control mechanism of regional haze pollution is necessary. Due to the existence of spatial spillover effects of haze pollution in China, environmental policies should break through regional restrictions of pollution governance. Governments should establish regional warning systems for haze pollution, including the creation of a governance office and an environmental information release platform.

Second, this study provides support for PHH. Therefore, we should actively adjust the method of introducing FDI and pay particular attention to the introduction of advanced green technologies or clean production technologies. Meanwhile, governments should set up sustainable development strategy and planning, and control highenergy consumption and high-pollution industries, and focus on the introduction of "clean" foreign investment.

Third, to realize the coordination development of economic and environmental pollution, governance policies should consider regional differences rather than applying the same policy to all regions. The economically 
developed regions should play the role of demonstrative effects and diffusion effects of pollution governance.

\section{Acknowledgements}

This study was supported by the National Science Foundation of China (No. 61173052), the Research Planning Foundation in Humanities and Social Sciences of the Ministry of Education of China (No. 13YJAZH044), and Guangdong Soft Science Item (No. 2013B070206002). We would like to thank Battelle Memorial Institute, Center for International Earth Science Information Network (CIESIE) for offering $\mathrm{PM}_{2.5}$ data for this study.

\section{References}

1. CMA (CHINA METEOROLOGICAL ADMINISTRATION). Specifications for the Surface Meteorological Observations. Meteorological Press, Beijing, 2013 [In Chinese].

2. GAO M., GUTTIKUNDA S.K., CARMICHAEL G.R., WANG Y., LIU Z., STANIER C.O., SAIDE P.E., YU M. Health impacts and economic losses assessment of the 2013 severe haze event in Beijing area. Sci. Total. Environ. 511, 553, 2015.

3. HO R.C., ZHANG M.W., HO C.S., PAN F., LU Y., SHARMA V.K. Impact of 2013 south Asian haze crisis: study of physical and psychological symptoms and perceived dangerousness of pollution level. Bmc. Psychiatry. 14, 81, 2014.

4. MA J., XU X., ZHAO C., YAN P. A review of atmospheric chemistry research in China: photochemical smog, haze pollution, and gas-aerosol interactions. Adv. Atmos. Sci. 29 (5), 1006, 2012.

5. VAN DONKELAAR A., MARTIN R.V., BRAUER M., KAHN R., LEVY R., VERDUZCO C., VILLENEUVE P.J. Global estimates of ambient fine particulate matter concentrations from satellite-based aerosol optical depth: development and application. Environ. Health. Persp. 118, (6), 847, 2010

6. WANG L., XU J., YANG J., ZHAO X., WEI W., CHENG D., PAN X., SU J. Understanding haze pollution over the southern Hebei area of China using the CMAQ model. Atmos. Environ. 56, 69, 2012.

7. WANG Y., YAO L., WANG L., LIU Z., JI D., TANG G., ZHANG J., SUN Y., HU B., XIN J. Mechanism for the formation of the January 2013 heavy haze pollution episode over central and eastern China. Sci China: Earth Sci. 57, (1), 14, 2014.

8. JAFFE A.B., PETERSON S.R., PORTNEY P.R., STAVINS R.N. Environmental regulation and the competitiveness of U.S. manufacturing: what does the evidence tell us. J. Econ. Lit. 33, 132, 1995.

9. WHEELER D. Foreign investment and air pollution in developing countries. J. Environ. Dev. 10 (3), 225, 2001.

10. SMARZYNSKA B., WEI S. Pollution havens and foreign direct investment: dirty secret or popular myth? Contrib. Econ. Anal. Policy. 3 (2), 1, 2004.

11. LIST J.A., CO C.Y. The effects of environmental regulations on foreign direct investment. J. Environ. Econ. Manag. 40 (1), 1, 2000.

12. HE J. Pollution haven hypothesis and environmental impacts of foreign direct investment: the case of industrial emission of sulfur dioxide $\left(\mathrm{SO}_{2}\right)$ in Chinese provinces. Ecol. Econ. 60

\section{(1), 228, 2006.}

13. WAGNER U.J., TIMMINS C.D. Agglomeration effects in foreign direct investment and the pollution haven hypothesis. Environ. Resour. Econ. 43 (2), 231, 2009.

14. COLE M.A., ELLIOTT R.J.R., ZHANG J. Growth, foreign direct investment, and the environment: evidence from Chinese cities. J. Reg. Sci. 51 (1), 121, 2011.

15. CHUNG S. Environmental regulation and foreign direct investment: evidence from South Korea. J. Dev. Econ. 108, 222, 2014.

16. LAU L., CHOONG C., ENG Y. Investigation of the environmental Kuznets curve for carbon emissions in Malaysia: do foreign direct investment and trade matter? Energ Policy. 68, 490, 2014.

17. BIRDSALL N., WHEELER D. Trade policy and industrial pollution in Latin America: where are the pollution havens? J. Environ. Dev. 2 (1), 137, 1993.

18. LIANG F.H. Does foreign direct investment harm the host country's environment evidence from China. Acad. Manag. 14, 38, 2005.

19. WALTER I., UGELOW J.L. Environmental policies in developing countries. Ambio. 8, 102, 1979.

20. ESKELAND G.S., HARRISON A.E. Moving to greener pastures multinationals and the pollution haven hypothesis. J. Dev. Econ. 70 (1), 1, 2003.

21. DONG B., GONG J., ZHAO X. FDI and environmental regulation: pollution haven or a race to the top? J. Reg. Econ. 41 (2), 216, 2012.

22. TANG C.F., TAN B.W. The impact of energy consumption, income and foreign direct investment on carbon dioxide emissions in Vietnam. Energy. 79, 447, 2015.

23. GROSSMAN G.M., KRUEGER A.B. Environmental impacts of a North American free trade agreement. NBER Working Paper. 1991.

24. BAO Q., CHEN Y., SONG L. Foreign direct investment and environmental pollution in China: a simultaneous equations estimation. Environ. Dev. Econ. 16 (1), 71, 2011.

25. LAN J., KAKINAKA M., HUANG X. Foreign direct investment, human capital and environmental pollution in China. Environ. Resour. Econ. 51 (2), 255, 2012.

26. ANSELIN L. Spatial econometrics in RSUE: retrospect and prospect. Reg. Sci. Urban. Econ. 37 (4), 450, 2007.

27. ANSELIN L. Local indicators of spatial association-LISA. Geogr Anal. 27 (2), 93, 1995.

28. GROSSMAN G.M., KRUEGER A.B. Economic growth and the environment. Quart. J. Econ. 110 (2), 353, 1995.

29. ANTWEILER W., COPELAND B.R., TAYLOR M.S. Is free trade good for the environment? Am. Econ. Rev. 91 (4), 877, 2001.

30. VAN DONKELAARA., MARTIN R.V., BRAUER M., BOY B.L. Use of satellite observations for long-term exposure assessment of global concentrations of fine particulate matter. Environ. Health. Persp. 123 (2), 135, 2015.

31. ANSELIN L., BERA A.K., FLORAX R. Simple diagnostic tests for spatial dependence. Reg. Sci. Urban. Econ. 26 (1), 77, 1996.

32. LI Q., SONG J., WANG E., HU H., ZHANG J., WANG Y. Economic growth and pollutant emissions in China: a spatial econometric analysis. Stoch. Environ. Res. Risk. Assess. 28 (2), 429, 2014.

33. ELHORST J.P. Specification and estimation of spatial panel data models. Int. Reg. Sci. Rev. 2 (26), 244, 2003.

34. PARK R., JACOB D., KUMAR N., YANTOSCA R. Regional visibility statistics in the United States: natural and transboundary pollution influences, and implications for the regional haze rule. Atmos. Environ. 40 (28), 5405, 2006. 